\title{
Multidrug Resistance Protein 2-Mediated Estradiol-17 $\beta$-D- glucuronide Transport Potentiation: In Vitro-in Vivo Correlation and Species Specificity
}

\author{
K. Herédi-Szabó, ${ }^{1}$ H. Glavinas, ${ }^{1}$ E. Kis, D. Méhn, G. Báthori, Z. Veres, L. Kóbori, \\ O. von Richter, K. Jemnitz, and P. Krajcsi \\ Solvo Biotechnology, Szeged, Hungary (K.H.-S., H.G., E.K., D.M., G.B., P.K.); Chemical Research Institute, HAS, \\ Budapest, Hungary (Z.V., L.K., K.J.); and Aicuris, Wuppertal, Germany (O.v.R.)
}

Received August 13, 2008; accepted December 31, 2008

\begin{abstract}
:
Multidrug resistance protein 2 (MRP2) is a multispecific organic anion transporter expressed at important pharmacological barriers, including the canalicular membrane of hepatocytes. At this location it is involved in the elimination of both endogenous and exogenous waste products, mostly as conjugates, to the bile. Estradiol-17 $\beta$-D-glucuronide $\left(E_{2} 17 \beta G\right)$, a widely studied endogenous substrate of MRP2, was shown earlier to recognize two binding sites of the transporter in vesicular transport assays. MRP2 modulators (substrates and nonsubstrates) potentiate the transport of $E_{2} 17 \beta G$ by MRP2. We correlated data obtained from studies of different complexities and investigated the species-
\end{abstract}

specific differences between rat and human MRP2-mediated transport. We used vesicular transport assays, sandwich-cultured primary hepatocytes, and in vivo biliary efflux in rats. Our results demonstrate that the rat Mrp2 transporter, unlike the human MRP2, transports $E_{2} 17 \beta G$ according to Michaelis-Menten type kinetics. Nevertheless, in the presence of modulator drugs $E_{2} 17 \beta G$ transport mediated by the rat transporter also shows cooperative kinetics as potentiation of $E_{2} 17 \beta G$ transport was observed in the vesicular transport assay. We also demonstrated that the potentiation exists both in rat and in human hepatocytes and in vivo in rats.
MRP2 (ABCC2, cMOAT) is a member of the ATP-binding cassette transporter family. This efflux protein is expressed on the apical membrane of polarized cells and can be detected in many tissues, including the intestine, liver, and kidneys (for review, see Nies and Keppler et al., 2007). MRP2 has wide substrate specificity. Although it transports hydrophobic compounds in the presence of glutathione (Evers et al., 2000) its role in transporting anionic compounds and sulfate, glucuronide, and glutathione conjugates is considered more important (König et al., 1999). This transporter is also responsible for the biliary elimination of certain endogenous conjugates, such as leukotrienes and conjugated bilirubins. Inhibition of MRP2-mediated transport of these compounds by drug molecules may result in accumulation of toxic waste products in hepatocytes, precipitating hepatotoxicity and cholestasis (Bode et al., 2002; Zelcer et al., 2006). Indeed, naturally occurring mutations leading to deficiencies of human MRP2 (Dubin-Johnson syndrome) and rat Mrp2 $\left(T R^{-}\right.$, Eisai

This work was supported in part by the Hungarian Office for Research and Technology [Grants OTKA T 043141, GVOP-2004-3.3.2.-2004-04-0001/3.0, GVOP-3.1.1.-2004-05-0506/3.0]; Emberi Erőforrás Fejlesztés (Human Resources Development)-Munka 00034/2003; and the European Union [Grants FP6-NoE 005137, LSBH-CT-2006-518246, LSHB-CT-2006-037499].

${ }^{1}$ K.H.-S. and H.G. contributed equally to this work.

Article, publication date, and citation information can be found at http://dmd.aspetjournals.org.

doi:10.1124/dmd.108.023895. hyperbilirubinemic rats) function (Buchler et al., 1996; Kartenbeck et al., 1996; Paulusma et al., 1997; Wada et al., 1998; Toh et al., 1999) caused increased blood levels of conjugated bilirubin metabolites. In addition, impaired canalicular excretion of a number of compounds in Mrp2-deficient rats has been shown (reviewed in Paulusma and Oude Elferink, 1997).

The transport of $E_{2} 17 \beta G$, an MRP2 substrate (Keppler et al., 1997), does not follow the classic Michaelis-Menten kinetics (Bodo et al., 2003; Zelcer et al., 2003; Zimmermann et al., 2008), rather the concentration dependence of transport follows sigmoid characteristics that can be explained by $E_{2} 17 \beta G$ binding to two different sites on MRP2. Zelcer et al. (2003) referred to these sites as S (substrate) and $\mathrm{M}$ (modulator) and created four groups of MRP2 interactors based on their effect on $\mathrm{E}_{2} 17 \beta \mathrm{G}$ transport. There are modulator compounds that are able to stimulate $\mathrm{E}_{2} 17 \beta \mathrm{G}$ transport in a dose-dependent manner by competing with $\mathrm{E}_{2} 17 \beta \mathrm{G}$ for the $\mathrm{M}$ site, which manifests as an increased transport of this substrate. $\mathrm{E}_{2} 17 \beta \mathrm{G}$ is also a substrate of rat Mrp2, and this transporter mediates its biliary excretion (Morikawa et al., 2000). The transport kinetics of $\mathrm{E}_{2} 17 \beta \mathrm{G}$ by rat Mrp2 is controversial as both hyperbolic and sigmoid transport profiles have been reported (reviewed in Borst et al., 2006a). Although most of these studies have been carried out in vesicular systems (reviewed in Borst et al., 2006a), the phenomenon has also been documented in cellular systems, albeit using substrates other than $\mathrm{E}_{2} 17 \beta \mathrm{G}$ (Huisman et al., 2005; Zimmermann et al., 2008). However, the physiological rele-

ABBREVIATIONS: MRP2/Mrp2 (ABCC2, cMOAT), multidrug resistance protein 2; $\mathrm{E}_{2} 17 \beta \mathrm{G}$, estradiol-17 $\beta$-D-glucuronide; Sf9, Spodoptera frugiperda ovarian; MOPS, 4-morpholinepropanesulfonic acid; HBSS, Hanks' balanced salt solution. 

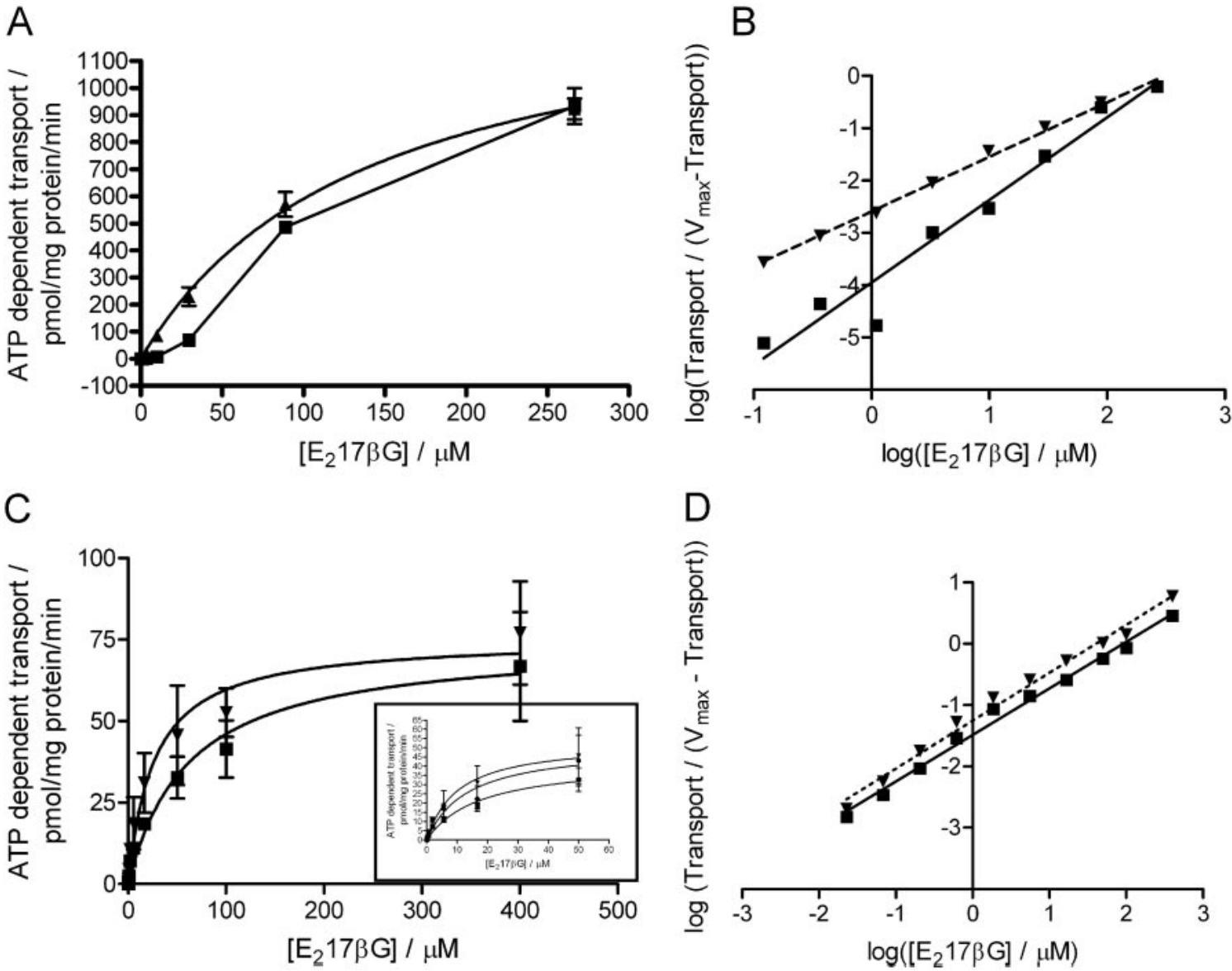

Fig. 1. Effect of indomethacin on the transport of $\mathrm{E}_{2} 17 \beta \mathrm{G}$ by human MRP2 (A and B) and rat Mrp2 (C and D). For human MRP2 in the absence of $100 \mu \mathrm{M}$ indomethacin (凹), the estimated apparent half-maximal rate $\left(K_{0.5}\right)$ was $150 \mu \mathrm{M}$, whereas in the presence of indomethacin $(\mathbf{\Lambda})$, the $K_{\mathrm{m}}$ is $139 \mu \mathrm{M}$ and the $V_{\max }$ is $1413 \mathrm{pmol} / \mathrm{mg}$ protein/min. $K_{\mathrm{m}}$ and $V_{\max }$ values for rat Mrp2 in the absence of indomethacin $(\mathbf{\square})$ are $61.5 \mu \mathrm{M}$ and $74.4 \mathrm{pmol} / \mathrm{mg}$ protein/min, respectively, whereas in the presence $(\mathbf{\Lambda})$ are $26.3 \mu \mathrm{M}$ and $75.3 \mathrm{pmol} / \mathrm{mg}$ protein/min, respectively. Inset in $\mathrm{C}$ shows the effect of $50 \mu \mathrm{M}$ indomethacin on $\mathrm{E}_{2} 17 \beta \mathrm{G}$ transport by rat Mrp2 at lower substrate concentrations $\left(K_{\mathrm{m}}=32.6 \mu \mathrm{M}\right)$. Representative Hill plots are shown for human and rat protein in B and D, respectively, for transport in the absence $(-)$ or in the presence (-- ) of $100 \mu \mathrm{M}$ indomethacin.

vance of this phenomenon is unclear, as the modulator-induced potentiation of Mrp2-mediated $\mathrm{E}_{2} 17 \beta \mathrm{G}$ transport, the most commonly studied probe substrate, has not been shown in vivo.

Another important question addressed is the difference in MRP2 substrate specificity between species. In preclinical studies mostly rodents are used to investigate the pharmacokinetics and toxicity of the compounds. Species specificity studies have been carried out for many MRP2 orthologs (Ninomiya et al., 2005, 2006; Zimmermann et al., 2008; Shilling et al., 2006). However, detailed studies that included membrane as well as cellular experimental systems have only been performed for the human and the mouse protein (Zimmermann et al., 2008).

In the present study, we investigated the correlation between data generated in experimental systems of different complexities: vesicular transport assay, sandwich-cultured rat and human hepatocytes, and in vivo rat studies. The second aim was application of the vesicular system and the sandwich-cultured hepatocytes to reveal differences between transporter orthologs of human and rat origin.

\section{Materials and Methods}

Materials. $\left[{ }^{3} \mathrm{H}\right]$ Estradiol-17 $\beta$-D-glucuronide $\left(\mathrm{E}_{2} 17 \beta \mathrm{G}\right)$ was purchased from PerkinElmer Life and Analytical Sciences (Waltham, MA). Recombinant baculovirus encoding wild-type human MRP2 was a kind gift from Balázs Sarkadi and András Váradi (Institute of Enzymology, Budapest, Hungary). Recombinant baculovirus harboring the rat Mrp2 cDNA was obtained from
Bruno Stieger and Peter Meier (University Hospital, Zurich, Switzerland) (Madon et al., 1997). All other chemicals and unlabeled compounds were purchased from Sigma-Aldrich (St. Louis, MO).

Expression of Human MRP2 and Rat Mrp2 in Insect Cells. Sf9 cells were cultured and infected with the recombinant baculovirus stocks as described earlier (Bakos et al., 2000).

Membrane Preparation. Membrane vesicle preparations expressing the human or rat form of ABCC2 (MRP2/Mrp2-Sf9) were prepared by Solvo Biotechnology (Szeged, Hungary) from baculovirus-infected Sf9 cells essentially as described previously (Bodo et al., 2003). Membrane protein content was determined using the BCA method (Pierce Biotechnology, Rockford, IL). The presence of the human and rat MRP2/Mrp2 transporter was confirmed with Western blotting, using the MRP2-specific monoclonal antibody, $\mathrm{M}_{2} \mathrm{III}-5$ (Alexis Corporation, Lausen, Switzerland).

Vesicular Transport Assay. Inside-out membrane vesicles were incubated in the presence or absence of $4 \mathrm{mM}$ ATP. For $\mathrm{E}_{2} 17 \beta \mathrm{G}$ vesicular transport, the measurements were carried out in $7.5 \mathrm{mM} \mathrm{MgCl}, 40 \mathrm{mM}$ MOPS-Tris, $\mathrm{pH} 7.0$, and $70 \mathrm{mM} \mathrm{KCl}$ at $37^{\circ} \mathrm{C}$ for $2 \mathrm{~min}$. The uptake was linear in this time frame. The transport was stopped by the addition of cold wash buffer $(40 \mathrm{mM}$ MOPS-Tris, $\mathrm{pH} 7.0$, and $70 \mathrm{mM} \mathrm{KCl}$ ), and the samples were immediately transferred to class B glass fiber filters, $1-\mu \mathrm{M}$ pore size (Millipore Corporation, Billerica, MA). Filters were washed with $200 \mu \mathrm{l}$ of ice-cold wash buffer five times, and radioactivity retained on the filter was measured by liquid scintillation counting. ATP-dependent transport was calculated by subtracting the values obtained in the absence of ATP from those in the presence of ATP.

Preparation and Culture of Primary Human and Rat Hepatocytes. Human liver tissues were obtained from kidney transplant donors by a quali- 
TABLE 1

Concentration of modulators causing maximal potentiation of $E_{2} 17 \beta G$ transport in the assays used

\begin{tabular}{|c|c|c|c|c|}
\hline & \multicolumn{4}{|c|}{ Modular Concentration/Maximal Effect } \\
\hline & MRP2 VT & Rat Mrp2 VT & MRP2 Sandwich & Rat Mrp2 Sandwich \\
\hline & \multicolumn{4}{|c|}{$\mu M / \%$ of control } \\
\hline Indomethacin & $100 / 750$ & $270 / 510$ & $10 / 220$ & $100 / 325$ \\
\hline Probenecid & $330 / 265$ & $1100 / 280$ & $50 / 158$ & $100 / 130$ \\
\hline Benzbromarone & $10 / 430$ & $11 / 155$ & $1 / 182$ & $10 / 155$ \\
\hline Sulfasalazine & $35 / 430$ & $110 / 360$ & $10 / 250$ & $10 / 170$ \\
\hline
\end{tabular}

VT, vesicular transport.

fied medical staff member from the Transplantation and Surgical Clinic, Semmelweis University of Budapest, as rejected donor livers. The human livers were inappropriate for transplantation for any reason. Permission of the Hungarian Regional Committee of Science and Research Ethics was obtained to use human tissues for scientific purposes. All studies involving human tissue followed the tenets of the Declaration of Helsinki. Hepatocytes were prepared by a three-step perfusion procedure. Human liver samples were first flushed with $\mathrm{Ca}^{2+}$-free Earle's balanced salt solution containing EGTA and then with the same buffer without chelating agent and finally with Earle's balanced salt solution containing $\mathrm{Ca}^{2+}$ and type IV collagenase (Sigma-Aldrich). Perfusions were carried out at $37^{\circ} \mathrm{C}, \mathrm{pH} 7.4$, as described by Bayliss and Skett (1996). Rat hepatocytes were prepared from male Wistar rats (200-250 g) (Charles River, Budapest, Hungary) similarly to the method described above. Cell viability $(>90 \%)$ was determined by trypan blue exclusion. All procedures were approved by the institutional animal care and use committee.

Hepatocytes were plated at a density of $2 \times 10^{6}$ cells/dish in $30-\mathrm{mm}$ Petri dishes precoated with $0.15 \mathrm{ml}$ of rat tail collagen type I solution $(1.6 \mathrm{mg} / \mathrm{ml})$ in Williams' Medium E containing 5\% of fetal calf serum, $100 \mathrm{nM}$ insulin, 2.5 $\mu \mathrm{g} / \mathrm{ml}$ amphotericin $\mathrm{B}, 0.1 \mathrm{mg} / \mathrm{ml}$ gentamicin, $30 \mathrm{nM} \mathrm{Na}_{2} \mathrm{SeO}_{3}$, and $0.1 \mu \mathrm{M}$ dexamethasone. The medium was aspirated, and cells were overlaid with 200 $\mu \mathrm{l}$ of ice-cold, neutralized rat tail collagen type I solution $(1.5 \mathrm{mg} / \mathrm{ml}, \mathrm{pH} 7.4)$ $24 \mathrm{~h}$ after plating, to achieve sandwich configuration. Williams' Medium E supplemented with insulin, gentamicin, dexamethasone, and $\mathrm{Na}_{2} \mathrm{SeO}_{3}$ was placed on the top of the gelled collagen layer $45 \mathrm{~min}$ after overlay.

MRP2/Mrp2 Transport Assay. Efflux studies in sandwich-cultured hepatocytes were performed by the modified method of Liu et al. (1999). In brief, hepatocytes cultured in a sandwich configuration for $48 \mathrm{~h}$ (rat) or 5 days (human) were incubated with $0.5 \mathrm{ml}$ of $1 \mu \mathrm{M}\left[{ }^{3} \mathrm{H}\right] \mathrm{E}_{2} 17 \beta \mathrm{G}$ for $10 \mathrm{~min}$ at $37^{\circ} \mathrm{C}$ in humidified atmosphere of $95 \%$ air- $5 \% \mathrm{CO}_{2}$. Then the loading medium was removed, and the cells were rinsed three times with $2.0 \mathrm{ml}$ of ice-cold standard or $\mathrm{Ca}^{2+}, \mathrm{Mg}^{2+}$-free HBSS and incubated with $0.5 \mathrm{ml}$ of standard or $\mathrm{Ca}^{2+}, \mathrm{Mg}^{2+}$-free HBSS supplemented with the modulator compounds or the vehicle for $20 \mathrm{~min}$. The modulators were present only in the efflux period of the experiments to avoid alteration of substrate uptake. The amount of $\mathrm{E}_{2} 17 \beta \mathrm{G}$ in the efflux medium was analyzed by scintillation counting. The transport of $\mathrm{E}_{2} 17 \beta \mathrm{G}$ into the canalicular networks was determined by subtracting the amount of $\mathrm{E}_{2} 17 \beta \mathrm{G}$ in standard HBSS from that in the $\mathrm{Ca}^{2+}, \mathrm{Mg}^{2+}$-free HBSS. The nonspecific $\left[{ }^{3} \mathrm{H}\right] \mathrm{E}_{2} 17 \beta \mathrm{G}$ binding was taken into consideration by subtracting radioactivity measured in the efflux medium of Petri dishes with two collagen layers and without hepatocytes from that obtained in the presence of hepatocytes.

In Vivo Studies. Male Wistar rats (Charles River) weighing 250 to $300 \mathrm{~g}$ were used for in vivo Mrp2 interaction studies. All procedures were approved by the institutional animal care and use committee. The rats had free access to general food and water and were maintained in a temperature-controlled facility with a 12-h light/dark cycle for at least 1 week. Before the experiment was started, the animals were fasted overnight but were allowed free access to water. Under urethane anesthesia ( $1 \mathrm{~g} / \mathrm{kg}$ i.p.) the common bile duct was cannulated with a polyethylene (PE-10) tube after laparotomy. Saline solution ( $2 \mathrm{ml}$ s.c.) was administered every hour to maintain liquid equilibrium of rats. After the experiments, the rats were sacrificed by cardiac puncture under anesthesia.

Treatment of rats was started after $30 \mathrm{~min}$ of surgery. Tracer doses of $\left[{ }^{3} \mathrm{H}\right] \mathrm{E}_{2} 17 \beta \mathrm{G}$ in $300 \mu \mathrm{l}$ of saline were coadministered intraperitoneally with the modulator compounds. Control rats received the $\left[{ }^{3} \mathrm{H}\right] \mathrm{E}_{2} 17 \beta \mathrm{G}$ and the vehicle only. Bile samples were collected every $10 \mathrm{~min}$ for $120 \mathrm{~min}$, every $20 \mathrm{~min} 2$ more hours, and every $30 \mathrm{~min}$ for an addition hour into preweighed tubes. Then the amount of $\mathrm{E}_{2} 17 \beta \mathrm{G}$ in the bile samples was determined by scintillation counting.

Data Analysis. Vesicular transport assays were run in duplicates. Data are presented as mean \pm S.D. For data analysis, GraphPad Prism (version 4.0; GraphPad Software Inc., San Diego, CA) was applied according to the equations as described in the following. $K_{\mathrm{m}}$ and $V_{\max }$ values from direct transport measurements were calculated using the Michaelis-Menten equation, after estimating the number of binding sites from the Hill plot:

$$
V=\frac{V_{\max } x[S]}{[S]+K_{\mathrm{m}}}
$$

where $V$ is velocity (picomoles of substrate per milligram of protein per minute), $V_{\max }$ is maximal velocity, $[S]$ is substrate concentration (micromolar), and $K_{\mathrm{m}}$ is the Michaelis-Menten constant. The results of the competition-type vesicular transport assays were analyzed using the Hill equation (variable slope sigmoid equation):

$$
V=V_{\text {min }}+\frac{V_{\text {max }}-V_{\text {min }}}{1+10^{\left(\log E C_{50}+[A]\right) n_{H}}}
$$

where $V$ is velocity (picomoles of substrate per milligram of protein per minute), $V_{\min }$ is minimal velocity (fully inhibited transport), $V_{\max }$ is maximal velocity (in the absence of inhibitor), $\mathrm{EC}_{50}$ is the ligand concentration producing $50 \%$ of maximal response (efficacy), $[A]$ is the actual test drug concentration, and the Hill slope is the parameter characterizing the degree of cooperativity.

\section{Results}

Kinetics of Human and Rat MRP2/Mrp2-Mediated $E_{2} 17 \beta G$ Transport in Vesicular Transport Assay. Figure 1 shows the concentration dependence of human and rat MRP2/Mrp2-mediated $\mathrm{E}_{2} 17 \beta \mathrm{G}$ transport. The transport follows classic Michaelis-Menten kinetics for rat Mrp2 (Fig. 1C), whereas a rather sigmoid shaped curve characterizes the transport by the human form (Fig. 1A), an indication for the presence of cooperative binding sites. The Hill numbers calculated are 1.58 and 0.98 for the human and the rat protein, respectively (Fig. 1, B and D). The $K_{0.5}$ value determined for MRP2 is $\sim 150 \mu \mathrm{M}$, whereas in the presence of $100 \mu \mathrm{M}$ indomethacin the saturation curve of human MRP2 becomes a Michaelis-Menten-type hyperbolic curve, with a $K_{\mathrm{m}}$ value of $139 \mu \mathrm{M}$ and a Hill number of 1.04. At the same time the $K_{\mathrm{m}}$ value of the rat Mrp2 curve shifts from 61.5 to $26.3 \mu \mathrm{M}$ in the presence of $100 \mu \mathrm{M}$ indomethacin, whereas no change was observed in the Hill number. The experiment was repeated in the presence of $50 \mu \mathrm{M}$ indomethacin at lower $\mathrm{E}_{2} 17 \beta \mathrm{G}$ concentrations and for rat Mrp2, and the tendency of decreasing $K_{\mathrm{m}}$ value with increasing indomethacin concentration was confirmed (Fig. 1C, inset; $K_{\mathrm{m}}=32.6 \mu \mathrm{M}$ ).

Table 1 and Fig. 2 summarize the results of the human and rat MRP2/Mrp2-mediated $\mathrm{E}_{2} 17 \beta \mathrm{G}$ transport in the presence of different modulator molecules. These compounds dose dependently potentiated 

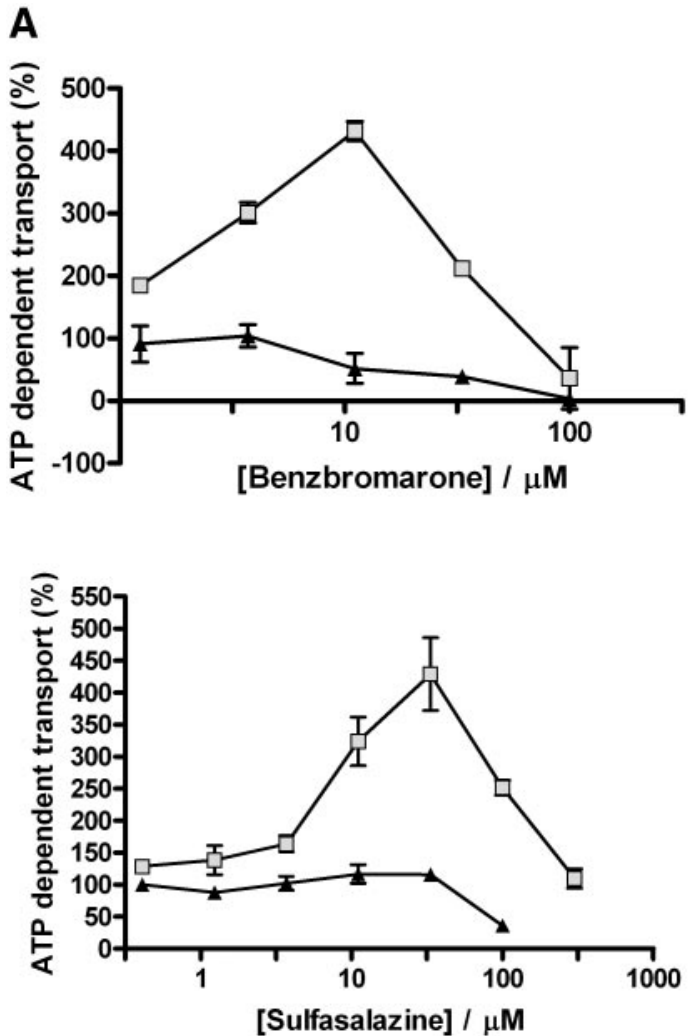

B
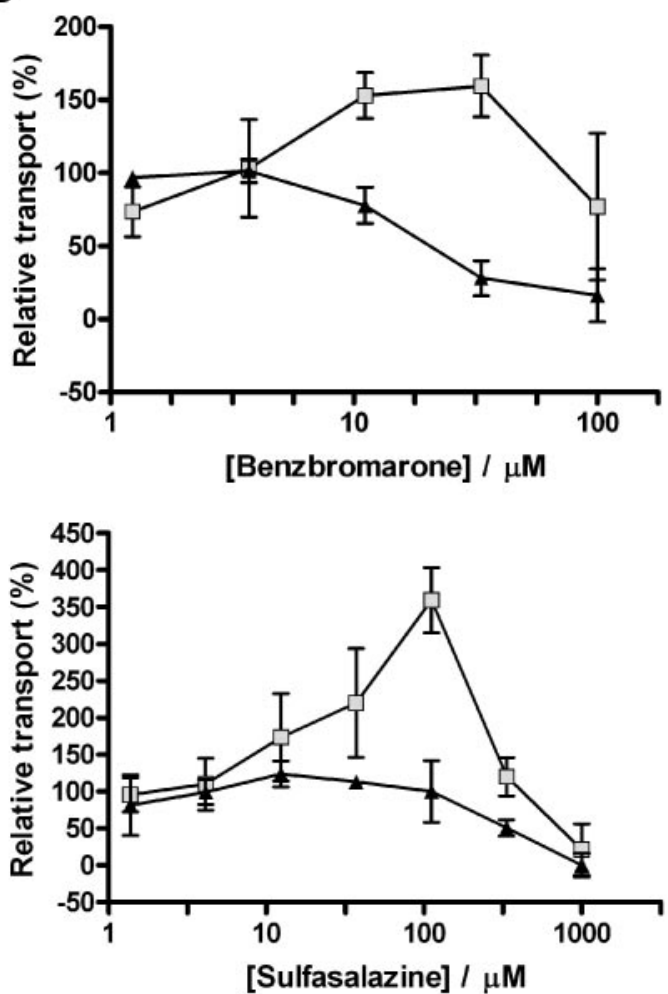
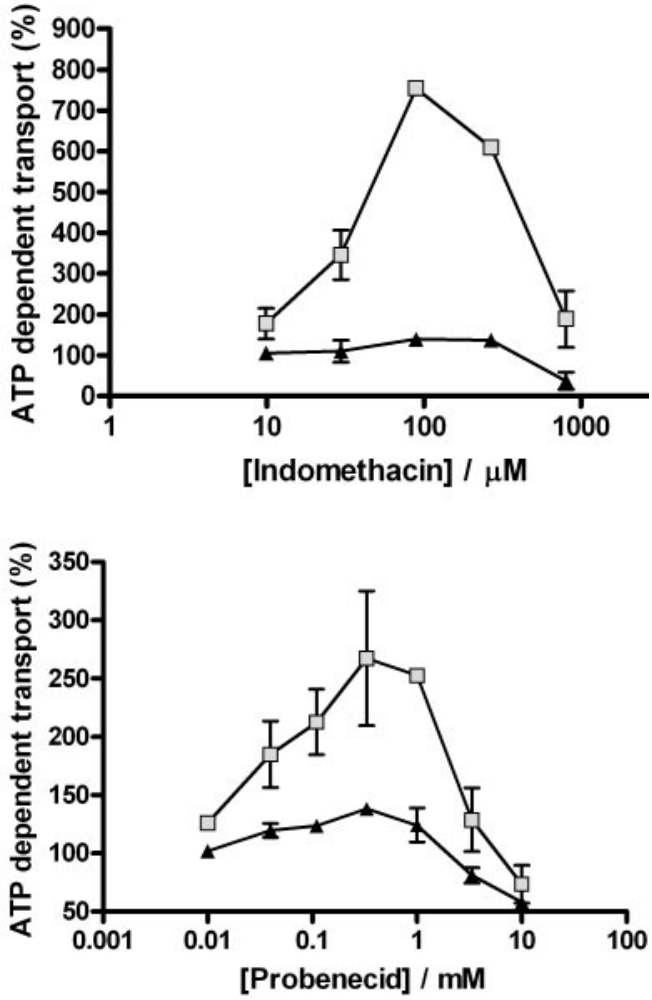

FIG. 2. Vesicular transport of $\mathrm{E}_{2} 17 \beta \mathrm{G}$ by human and rat MRP2/ Mrp2 transporter in the presence of modulators. A, effect of modulators on the transport of $\mathrm{E} 217 \beta \mathrm{G}$ by MRP2. The effect is investigated in the presence of $1 \mu \mathrm{M}$ $\mathrm{E} 217 \beta \mathrm{G}$ (圈) and $50 \mu \mathrm{M}$ E2 $17 \beta \mathrm{G}$ $(\mathbf{\Lambda})$. B, effect of modulators on the transport of $\mathrm{E} 217 \beta \mathrm{G}$ by rat Mrp2 The effect is investigated in the presence of $1 \mu \mathrm{M} \mathrm{E} 217 \beta \mathrm{G}$ (畻) and $50 \mu \mathrm{M}$ E217 $\beta \mathrm{G}(\mathbf{\Delta})$.

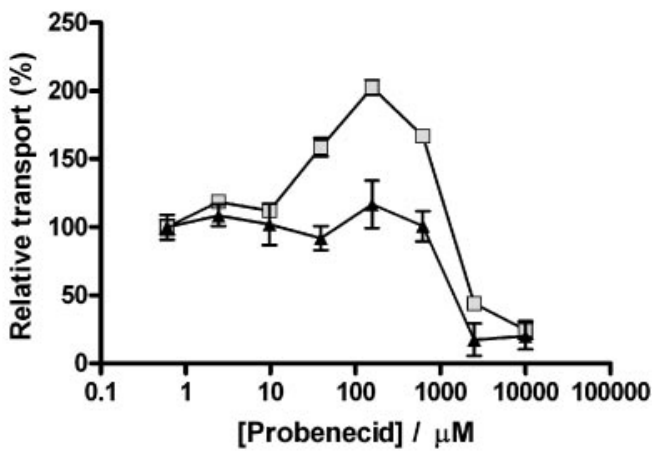

the transport of $E_{2} 17 \beta G$. In both species, indomethacin proved to be the most efficacious modulator of $E_{2} 17 \beta G$ transport among the compounds investigated, followed by sulfasalazine and probenecid. In these cases no large differences were observed between the maximal stimulatory effects relative to control values. Benzbromarone also stimulated the transport of $\mathrm{E}_{2} 17 \beta \mathrm{G}$ in both species; however, the potentiation was more pronounced for the human protein compared with the rat protein $(430 \%$ versus $155 \%)$.

Effect of Modulator Drugs on $E_{2} 17 \beta G$ Transport Measured in Sandwich-Cultured Human and Rat Hepatocytes. Figure 3 shows the canalicular efflux of $E_{2} 17 \beta G$ in sandwich-cultured rat and human hepatocytes in the presence of different concentrations of modulators. 

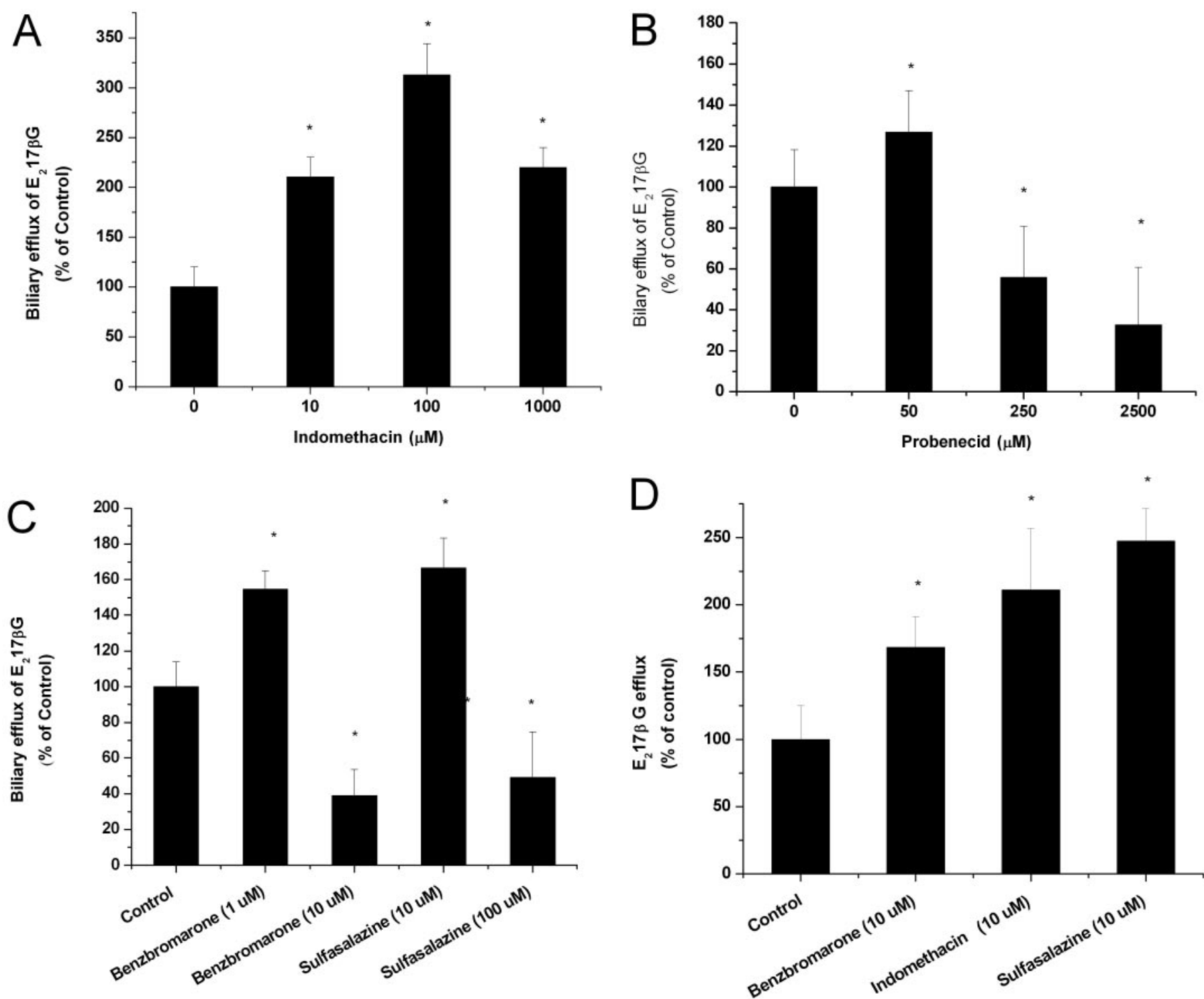

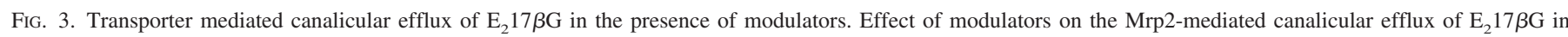

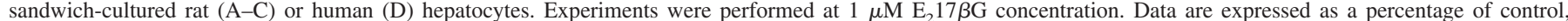

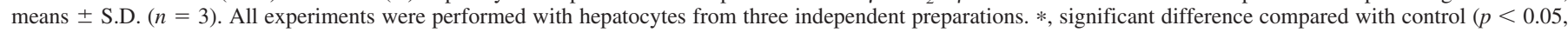
determined by Student's $t$ test).

Because the substrate uptake occurred in the absence of the modulators, these compounds could modulate the efflux transporters only. In rat hepatocytes indomethacin significantly elevated the canalicular transport of $E_{2} 17 \beta G$ at all concentrations (Fig. 2A). Probenecid (Fig. 2B) and benzbromarone and sulfasalazine (Fig. 2C) potentiated the transport at low concentrations $(50,1$, and $10 \mu \mathrm{M}$, respectively), but at higher concentrations (250 and $2500 \mu \mathrm{M}$ and 10 and $100 \mu \mathrm{M}$, respectively) inhibited the biliary transport of $\mathrm{E}_{2} 17 \beta \mathrm{G}$. Likewise, in human hepatocyte cultures benzbromarone $(10 \mu \mathrm{M})$, indomethacin $(10 \mu \mathrm{M})$, and sulfasalazine $(10 \mu \mathrm{M})$ potentiated the biliary efflux of $\mathrm{E}_{2} 17 \beta \mathrm{G}$ (Fig. 2D).

In Vivo Efflux Experiments. Indomethacin significantly increased the efflux of $E_{2} 17 \beta G$ without influencing the bile flow at a $5 \mathrm{mg} / \mathrm{kg}$ dose. The half-life was decreased by $40 \%$ (Fig. 4A). Indomethacin significantly increased the biliary efflux of $\mathrm{E}_{2} 17 \beta \mathrm{G}$ shortly after administration, as shown in Fig. 4B.

Benzbromarone also increased the biliary elimination of $\mathrm{E}_{2} 17 \beta \mathrm{G}$ (Fig. 4C). The half-life of $E_{2} 17 \beta G$ decreased significantly even at a dose of $10 \mathrm{mg} / \mathrm{kg}$, which could be further decreased by higher doses. Similar to the observations with indomethacin, the elimination rate peaked shortly after administration of benzbromarone (Fig. 4D).

Probenecid significantly decreased the half-life of $\mathrm{E}_{2} 17 \beta \mathrm{G}$ at a 25 $\mathrm{mg} / \mathrm{kg}$ dose compared with control, but at a higher dose $(50 \mathrm{mg} / \mathrm{kg})$ the difference was not significant (Fig. 4E). Probenecid is choleretic even at a $25 \mathrm{mg} / \mathrm{kg}$ dose (Fig. 4F), which may explain the disappearance of the effect. Alternatively, the effect of probenecid is bellshaped in vivo, just as it is in vitro in the vesicular transport assay (Fig. 2B).

\section{DISCUSSION}

MRP2 transports many anionic drugs and drug metabolites that may interfere with the transport of endogenous MRP2 substrates, such as bilirubin glucuronide or $\mathrm{E}_{2} 17 \beta \mathrm{G}$ (Bode et al., 2002). In this article known MRP2 interactors were investigated for their effect on the transport of $\mathrm{E}_{2} 17 \beta \mathrm{G}$. We selected three different assay systems, vesicular transport assays, hepatocyte sandwich culture experiments 


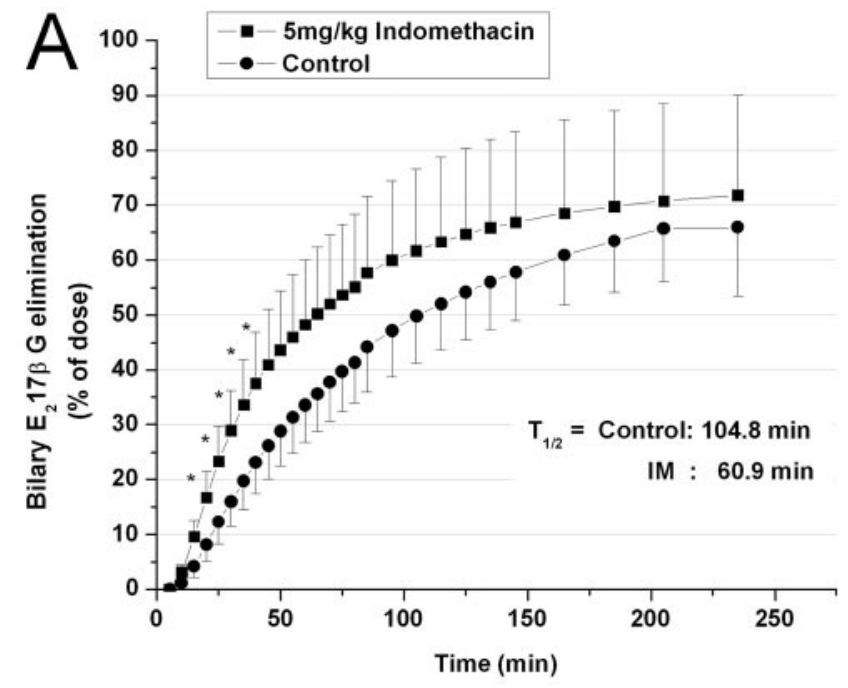

B
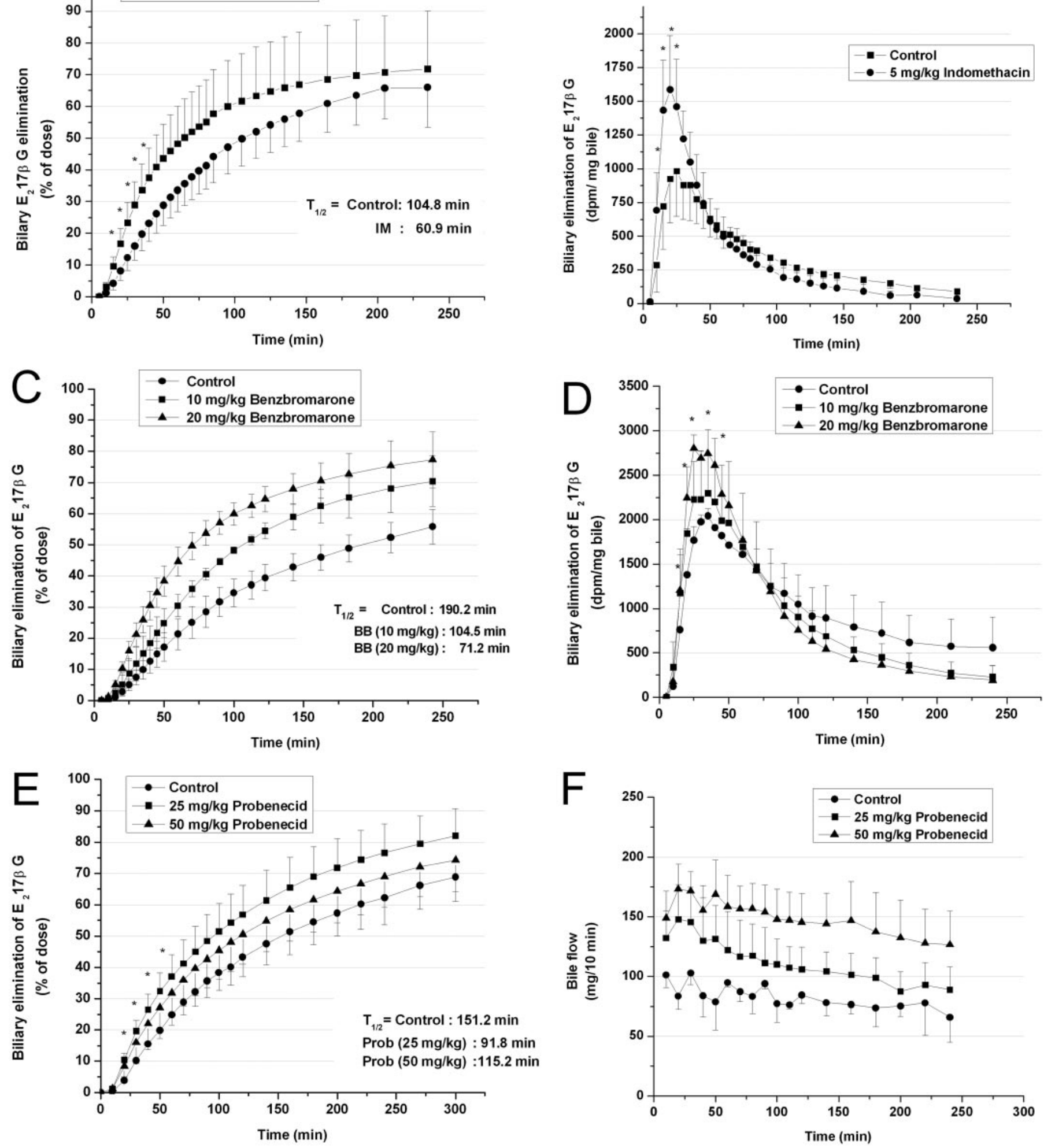

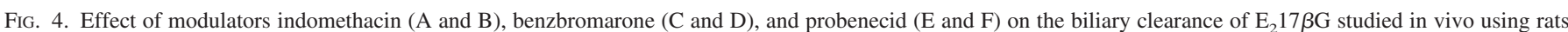
Each point represents the mean value \pm S.D. $(n=3)$.*, significant difference compared with control $(p<0.05$, determined by Student's $t$ test $)$.

to study differences in species specificity between human and rat, and in vivo rat studies to determine in vitro-in vivo correlations for rats.

Vesicular transport studies have shown a marked difference in the kinetics of the transport of $\mathrm{E}_{2} 17 \beta \mathrm{G}$, an important endogenous substrate of MRP2/Mrp2. The sigmoid transport curve and Hill plot data have shown that the human protein probably has two cooperative binding sites $(n=1.58)$, whereas the rat protein displayed noncooperative transport with a Hill number close to $1(n=0.98)$. There is a great deal of disagreement in data published on the MRP2/Mrp2mediated $\mathrm{E}_{2} 17 \beta \mathrm{G}$ transport (reviewed in Borst et al., 2006b). Single 
digit $K_{\mathrm{m}}$ values were reported by a study (Cui et al., 1999) with Michaelis-Menten type kinetics for the human protein. The study by Zelcer et al. (2003), similarly to our data, showed cooperative interaction with lower affinities $\left(K_{0.5}=120 \mu \mathrm{M}\right)$. A study using human canalicular membrane vesicles showed Michaelis-Menten type kinetics with a $K_{\mathrm{m}}$ of $364 \mu \mathrm{M}$ (Shilling et al., 2006). For rat protein classic Michaelis-Menten type kinetics was shown (Borst et al., 2006b). In contrast, two laboratories reported cooperative transport of $E_{2} 17 \beta G$ by rat Mrp2. One of them demonstrated a sigmoidal transport with a Hill number of 1.16 (Ninomiya et al., 2005; also reviewed in Borst et al., 2006b), whereas the other group calculated a Hill number of 1.5 (Gerk et al., 2004). The reported $K_{\mathrm{m}}$ values range from single digit (Cui et al., 1999; Ito et al., 2001) through double digit (Borst et al., 2006b) to triple digit numbers (Shilling et al., 2006). Our data are similar to results obtained using rat Mrp2-Sf9 for which MichaelisMenten type kinetics and double digit $K_{\mathrm{m}}\left(K_{\mathrm{m}}=16 \mu \mathrm{M}\right)$ was found (Borst et al., 2006b).

We have shown that the phenomenon of cooperativity is not restricted to the human protein because a heterotropic effect on rat Mrp2 $\mathrm{E}_{2} 17 \beta \mathrm{G}$ transport by many compounds is clearly seen (Fig. 2). The effect of modulators is more dramatic on the human MRP2-mediated $\mathrm{E}_{2} 17 \beta \mathrm{G}$ transport as shown in Fig. 1A in which indomethacin converts the sigmoidal transport kinetics into hyperbolic kinetics. The rat Mrp2-mediated transport follows Michaelis-Menten kinetics rather than a sigmoid type (Fig. 1C). However, in the presence of $100 \mu \mathrm{M}$ indomethacin, the $K_{\mathrm{m}}$ value decreases from 61.5 to $26.3 \mu \mathrm{M}$, explaining the potentiation phenomenon observed in the vesicular transport assay (Fig. 2).

It has been suggested (Borst et al., 2006b) that the differences observed in the rat Mrp2 data are due to differences in the membrane lipid composition. However, we have repeated $E_{2} 17 \beta G$ transport using MDCKII membranes overexpressing rat Mrp2 and obtained Michaelis-Menten type kinetics (data not shown). Likewise, one of the articles cited (Shilling et al., 2006) used rat canalicular membrane vesicles membranes and observed hyperbolic kinetics.

In general, we have seen that the maximal stimulatory concentrations are higher for the rat transporter than those for the human transporter. It is also evident that the compounds have lower affinity for the modulating site on the rat protein than for the equivalent site on human MRP2 (Table 1). Differences in cooperativity have been found for MRP2 transporters from rat and dog (Ninomiya et al., 2005) and human and mouse (Zimmermann et al., 2008). The potentiating effect of different substrates depends on the concentration of $E_{2} 17 \beta G$. At $1 \mu \mathrm{M} \mathrm{E} \mathrm{E}_{2} 17 \beta \mathrm{G}$ potentiation is seen, whereas at higher drug concentrations inhibition is seen (Fig. 4). At $50 \mu \mathrm{M} \mathrm{E} \mathrm{E}_{2} 17 \beta \mathrm{G}$ only inhibition is seen (Fig. 2). With the two-site model proposed earlier (Zelcer et al., 2003), it can be envisioned that at lower (1 $\mu \mathrm{M})$ $\mathrm{E}_{2} 17 \beta \mathrm{G}$ concentrations the site used for the heterotropic effect is available for the modulator drugs. At greater $(50 \mu \mathrm{M}) \mathrm{E}_{2} 17 \beta \mathrm{G}$ concentrations both sites are occupied by the substrate $\mathrm{E}_{2} 17 \beta \mathrm{G}$. At greater drug concentrations, however, inhibition takes place without the potentiation phase of lower drug concentration, which suggests that at these respective substrate and modulator concentrations the modulator competes efficiently with $\mathrm{E}_{2} 17 \beta \mathrm{G}$ for the transport site. These observations should be taken into consideration in the design of drug-transporter interaction assays.

The phenomenon of cooperativity in MRP2/Mrp2-mediated transport is not unique to the vesicular system. The phenomenon has been demonstrated with transfected MDCKII cells (Zimmermann et al., 2008). Our data using various assay systems to investigate the transport of $E_{2} 17 \beta G$, the most thoroughly studied substrate, also substantiate the observation. The maximal potentiation values and concen- trations of $E_{2} 17 \beta G$ transport are summarized in Table 1. The concentrations used in the sandwich-cultured hepatocyte experiments are clinically relevant for all modulators, for indomethacin (Takeda et al., 2002), for probenecid (Dayton et al., 1963), for sulfasalazine (Yamasaki et al., 2008), and also for benzbromarone (Ito et al., 2004; product information for Urinorm, 2005; Torii Pharmaceutical Co. Ltd, Tokyo, Japan). The concentrations used in the vesicular transport studies are in the range used by other studies (Bodo et al., 2003; Zelcer et al., 2003). These concentrations model intracellular values. The hepatocyte uptakes of probenecid (Terasaki et al., 1986) and indomethacin (Morita et al., 2005) are at least partly transportermediated; thus, free intracellular concentrations may exceed the extracellular concentration of free dugs. Sulfasalazine is a compound with an extremely low passive permeability and its cellular uptake is inhibited by organic anion transport inhibitors (Liang et al., 2000). Therefore, it is likely that intracellular concentrations reach values shown to potentiate $\mathrm{E}_{2} 17 \beta \mathrm{G}$ transport in the vesicular assay. The $\mathrm{E}_{2} 17 \beta \mathrm{G}$ concentration of $1 \mu \mathrm{M}$ used in the sandwich culture experiments is justified by the low micromolar $K_{\mathrm{m}}$ of $\mathrm{E}_{2} 17 \beta \mathrm{G}$ uptake into hepatocytes and is within the range used in other studies (Brouwer et al., 1987; Shitara et al., 2003). Using another approach, Sasaki et al. (2004) correlated the in vivo biliary clearance and in vitro transcellular transport of $\mathrm{E}_{2} 17 \beta \mathrm{G}$, using rat organic anion-transporting peptide 4 (Slc21a10) and Mrp2 double-transfected MDCKII cells, a hepatocyte model for vectorial transport studies. They found that extrapolation from in vitro data resulted in the underestimation of the in vivo blood to bile disposition. However, as the rate-determining step in both in vitro and in vivo systems was shown to be the uptake process, the role of Mrp2 has not been taken into consideration. Our experimental design differed 2-fold from this study, because we 1) used modulators that potentiated MRP2/Mrp2 activity and 2) separated the uptake process from the efflux step; hence, we were able to examine the efflux step. Our results indicate that the MRP2/Mrp2mediated potentiation of $\mathrm{E}_{2} 17 \beta \mathrm{G}$ transport shown in the vesicular transport assay is present in the hepatocyte sandwich culture experiments and in vivo for the rat transporter for all compounds tested.

In summary, we have demonstrated for the first time that $\mathrm{E}_{2} 17 \beta \mathrm{G}$ transport potentiation by modulator drugs can also be observed in sandwich-cultured hepatocytes and in vivo biliary excretion experiments. Our data clearly show that the phenomenon of heterotropic cooperativity is physiologically and pharmacologically relevant. However, further studies are needed to establish the physiological and pharmacological significance of the phenomenon in vivo.

Acknowledgments. We are grateful to Drs. Balazs Sarkadi, András Váradi, and Bruno Stieger for providing the baculoviruses used in this work. The expert help of Judit Janossy, MSc, in reviewing and preparation of the manuscript is acknowledged.

\section{References}

Bakos E, Evers R, Sinkó E, Váradi A, Borst P, and Sarkadi B (2000) Interactions of the human multidrug resistance proteins MRP1 and MRP2 with organic anions. Mol Pharmacol 57:760768.

Bayliss MK and Skett P (1996) Human Cell Culture Protocols, pp 369-89, Humana Press, Totawa, NJ.

Bode KA, Donner MG, Leier I, and Keppler D (2002) Inhibition of transport across the hepatocyte canalicular membrane by the antibiotic fusidate. Biochem Pharmacol 64:151-158. Bodo A, Bakos E, Szeri F, Varadi A, and Sarkadi B (2003) Differential modulation of the human liver conjugate transporters MRP2 and MRP3 by bile acids and organic anions. J Biol Chem 278:23529-23537.

Borst P, Zelcer N, van de Wetering K, and Poolman B (2006a) On the putative co-transport of drugs by multidrug resistance proteins. FEBS Lett 580:1085-1093.

Borst P, Zelcer N, and van de Wetering K (2006b) MRP2 and 3 in health and disease. Cancer Lett 234:51-61.

Brouwer KL, Durham S, and Vore M (1987) Multiple carriers for uptake of $\left[{ }^{3} \mathrm{H}\right]$ estradiol-17 $\beta(\beta$ D-glucuronide) in isolated rat hepatocytes. Mol Pharmacol 32:519-523.

Büchler M, König J, Brom M, Kartenbeck J, Spring H, Horie T, and Keppler D (1996) cDNA cloning of the hepatocyte canalicular isoform of the multidrug resistance protein, cMrp, 
reveals a novel conjugate export pump deficient in hyperbilirubinemic mutant rats. $J$ Biol Chem 271:15091-15098.

Cui Y, König J, Buchholz JK, Spring H, Leier I, and Keppler D (1999) Drug resistance and ATP-dependent conjugate transport mediated by the apical multidrug resistance protein, MRP2, permanently expressed in human and canine cells. Mol Pharmacol 55:929-937.

Dayton PG, Yu TF, Chen W, Berger L, West LA, and Gutman AB (1963) The physiological disposition of probenecid, including renal clearance, in man, studied by an improved method for its estimation in biological material. J Pharmacol Exp Ther 140:278-286.

Evers R, de Haas M, Sparidans R, Beijnen J, Wielinga PR, Lankelma J, and Borst P (2000) Vinblastine and sulfinpyrazone export by the multidrug resistance protein MRP2 is associated with glutathione export. Br J Cancer 83:375-383.

Gerk PM, Li W, and Vore M (2004) Estradiol 3-glucuronide is transported by the multidrug resistance-associated protein 2 but does not activate the allosteric site bound by estradio 17-glucuronide. Drug Metab Dispos 32:1139-1145.

Huisman MT, Chhatta AA, van Tellingen O, Beijnen JH, and Schinkel AH (2005) MRP2 $(\mathrm{ABCC} 2)$ transports taxanes and confers paclitaxel resistance and both processes are stimulated by probenecid. Int J Cancer 116:824-829.

Ito K, Suzuki H, and Sugiyama Y (2001) Charged amino acids in the transmembrane domain are involved in the determination of the substrate specificity of rat Mrp2. Mol Pharmacol 59:1077-1085.

Kartenbeck J, Leuschner U, Mayer R, and Keppler D (1996) Absence of the canalicular isoform of the MRP gene-encoded conjugate export pump from the hepatocytes in Dubin-Johnson syndrome. Hepatology 23:1061-1066.

Keppler D, Leier I, and Jedlitschky G (1997) Transport of glutathione conjugates and glucuronides by the multidrug resistance proteins MRP1 and MRP2. Biol Chem 378:787-791.

König J, Nies AT, Cui Y, Leier I, and Keppler D (1999) Conjugate export pumps of the multidrug resistance protein (MRP) family: localization, substrate specificity, and MRP2mediated drug resistance. Biochim Biophys Acta 1461:377-394.

Liang E, Proudfoot J, and Yazdanian M (2000) Mechanisms of transport and structurepermeability relationship of sulfasalazine and its analogs in Caco-2 cell monolayers. Pharm Res 17:1168-1174

Liu X, LeCluyse EL, Brouwer KR, Gan LS, Lemasters JJ, Stieger B, Meier PJ, and Brouwer KL (1999) Biliary excretion in primary rat hepatocytes cultured in a collagen-sandwich configuration. Am J Physiol 277(1 Pt 1):G12-G21.

Madon J, Eckhardt U, Gerloff T, Stieger B, and Meier PJ (1997) Functional expression of the rat liver canalicular isoform of the multidrug resistance-associated protein. FEBS Lett 406:75-78

Morikawa A, Goto Y, Suzuki H, Hirohashi T, and Sugiyama Y (2000) Biliary excretion of $17 \beta$-estradiol $17 \beta$-D-glucuronide is predominantly mediated by cMOAT/MRP2. Pharm Res 17:546-552.

Morita N, Kusuhara H, Nozaki Y, Endou H, and Sugiyama Y (2005) Functional involvement of rat organic anion transporter 2 (Slc22a7) in the hepatic uptake of the nonsteroidal antiinflammatory drug ketoprofen. Drug Metab Dispos 33:1151-1157.

Nies AT and Keppler D (2007) The apical conjugate efflux pump ABCC2 (MRP2). Pflugers Arch 453:643-659.

Ninomiya M, Ito K, and Horie T (2005) Functional analysis of dog multidrug resistanceassociated protein 2 (Mrp2) in comparison with rat Mrp2. Drug Metab Dispos 33:225-232.

Ninomiya M, Ito K, Hiramatsu R, and Horie T (2006) Functional analysis of mouse and monkey multidrug resistance-associated protein 2 (Mrp2). Drug Metab Dispos 34:2056-2063.

Paulusma CC, Kool M, Bosma PJ, Scheffer GL, ter Borg F, Scheper RJ, Tytgat GN, Borst P
Baas F, and Oude Elferink RP (1997) A mutation in the human canalicular multispecific organic anion transporter gene causes the Dubin-Johnson syndrome. Hepatology 25:15391542

Paulusma CC and Oude Elferink RP (1997) The canalicular multispecific organic anion transporter and conjugated hyperbilirubinemia in rat and man. $J$ Mol Med 75:420-428.

Sasaki M, Suzuki H, Aoki J, Ito K, Meier PJ, and Sugiyama Y (2004) Prediction of in vivo biliary clearance from the in vitro transcellular transport of organic anions across a double-transfected Madin-Darby canine kidney II monolayer expressing both rat organic anion transporting polypeptide 4 and multidrug resistance associated protein 2. Mol Pharmacol 66:450-459.

Shilling AD, Azam F, Kao J, and Leung L (2006) Use of canalicular membrane vesicles (CMVs) from rats, dogs, monkeys and humans to assess drug transport across the canalicular membrane. J Pharmacol Toxicol Methods 53:186-197.

Shitara Y, Li AP, Kato Y, Lu C, Ito K, Itoh T, and Sugiyama Y (2003) Function of uptake transporters for taurocholate and estradiol $17 \beta$-D-glucuronide in cryopreserved human hepatocytes. Drug Metab Pharmacokinet 18:33-41.

Takeda M, Khamdang S, Narikawa S, Kimura H, Hosoyamada M, Cha SH, Sekine T, and Endou $\mathrm{H}$ (2002) Characterization of methotrexate transport and its drug interactions with human organic anion transporters. J Pharmacol Exp Ther 302:666-671.

Terasaki T, Tamai I, Takanosu K, Nakashima E, and Tsuji A (1986) Kinetic evidence for a common transport route of benzylpenicillin and probenecid by freshly prepared hepatocytes in rats. Influence of sodium ion, organic anions, amino acids and peptides on benzylpenicillin uptake. J Pharmacobiodyn 9:18-28.

Toh S, Wada M, Uchiumi T, Inokuchi A, Makino Y, Horie Y, Adachi Y, Sakisaka S, an Kuwano M (1999) Genomic structure of the canalicular multispecific organic aniontransporter gene (MRP2/cMOAT) and mutations in the ATP-binding-cassette region in DubinJohnson syndrome. Am J Hum Genet 64:739-746.

Wada M, Toh S, Taniguchi K, Nakamura T, Uchiumi T, Kohno K, Yoshida I, Kimura A, Sakisaka S, Adachi Y, et al. (1998) Mutations in the canalicular multispecific organic anion transporter (cMOAT) gene, a novel ABC transporter, in patients with hyperbilirubinemia II/Dubin-Johnson syndrome. Hum Mol Genet 7:203-207.

Yamasaki Y, Ieiri I, Kusuhara H, Sasaki T, Kimura M, Tabuchi H, Ando Y, Irie S, Ware J, Nakai $\mathrm{Y}$, et al. (2008) Pharmacogenetic characterization of sulfasalazine disposition based on NAT2 and ABCG2 (BCRP) gene polymorphisms in humans. Clin Pharmacol Ther 84:95-103.

Zelcer N, Huisman MT, Reid G, Wielinga P, Breedveld P, Kuil A, Knipscheer P, Schellens JH, Schinkel AH, and Borst P (2003) Evidence for two interacting ligand binding sites in human multidrug resistance protein 2 (ATP binding cassette C2). J Biol Chem 278:23538-23544.

Zelcer N, van de Wetering K, de Waart R, Scheffer GL, Marschall HU, Wielinga PR, Kuil A, Kunne C, Smith A, van der Valk M, et al. (2006) Mice lacking Mrp3 (Abcc3) have normal bile salt transport, but altered hepatic transport of endogenous glucuronides. J Hepatol 44:768 775

Zimmermann C, van de Wetering K, van de Steeg E, Wagenaar E, Vens C, and Schinkel AH (2008) Species-dependent transport and modulation properties of human and mouse multidrug resistance protein 2 (MRP2/Mrp2, ABCC2/Abcc2). Drug Metab Dispos 36:631-640.

Address correspondence to: Dr. Peter Krajcsi, Solvo Biotechnology, Gyár u 2, Budaörs, Hungary 2040. E-mail: krajcsi@solvo.hu 